\title{
The role of a clinical teacher in the context of changing medical education in Sri Lanka
}

\author{
Indrakumar J, Gunathilake S \\ Department of Medicine, Faculty of Medicine, Sri Jayawardenapura University, Kotte \\ Corresponding author: Dr. J. Indrakumar
}

Effective clinical teaching has many facets. Clinical knowledge, skills, good communication skills, empathy with patients, professionalism, and humanistic qualities comprise some of the qualities required of a good clinical teacher. One of the requirements of clinical teachers is that they should be competent clinicians. The role of a clinical teacher is really a complex task in terms of combining teaching activities with busy clinical commitments. Further it gets more complicated when considering the individual needs.

Medical education in Sri Lanka is in the process of changing as new methods of teaching have evolved. There is an increasing emphasis on student-centered learning where students are expected to take more responsibility of their own learning (1). Further, there have been changes in the area of assessments with new tools of assessments such as OSCE (Objective Structured Clinical Examination) and SEQ (Structured Essay Question) and best of five MCQ's having been introduced in medical schools. These changes have placed more complex demands on the clinical teachers changing the nature of their work tasks with new academic roles and diversification of existing roles (2). As such, teaching medical students becomes a challenging task that requires a clear insight into the duties of a modern teacher.

A common assumption is that all experienced clinicians are good teachers. However the reality is these are two different skills and may not go hand in hand. Although majority of clinicians in teaching hospitals are involved with active student teaching many have not received any formal instructions to fulfill this task successfully. In Sri Lanka when clinicians are appointed to teaching hospitals, their teaching experience or ability is not considered. They learn teaching skills on the job and generally have less chance of attending training programs. Due to the shortages in clinical examiners some medical faculties even use very junior clinicians with little or no teaching experience as clinical examiners. The Postgraduate institute of medicine (PGIM) and universities must attempt to organize training courses in medical teaching and student assessments for the inexperienced clinical teachers. The PGIM is in a position to have an annual training course in teaching skills for their newly board certified clinicians. Clinicians should be made aware of the medical curriculum and its objectives so that they can apply this knowledge during their teaching.

\section{Roles of a medical teacher}

1. Information Provider

Lecturer in classroom setting

Teacher in practical or clinical setting

2. Role model

On-the-job role model

Role model in the teaching setting

3. Facilitator

Mentor, personal advisor or tutor

Learning facilitator

4. Examiner (Assessor)

Planning or participating in formal examinations of students

Curriculum evaluator

5. Resources developer

Production of a study guide

Developing resource materials- computer based self learning, video or print

6. Planner

Curriculum planner

Course organizer 
Traditionally students believe that the teacher knows everything that was considered essential to know and as such it is the responsibility of the teacher to provide them with knowledge. Lectures are a cost effective tool and by making them more interactive, students could be stimulated and motivated to read more on the subject. During a lecture or a teaching ward round, the prime objective is to teach medical students, train them on the basic skills of history taking and physical examination and the process of clinical decision making. Although the internet has made it possible for the student to access relevant information freely, they need proper guidance on how to make sense of this overwhelming information. The western textbooks do not adequately cover illnesses that are confined to our country. Attempts have been taken to remedy this by two well known student textbooks, Davidson's Principles and Practice of Medicine and the Kumar and Clark's Text Book of Medicine by including authors and advisors from the Asian region. The teachers in our universities also must attempt to produce books, monographs and handouts on selected areas specific to the region. Proper and detailed management of common conditions seen in our country like dengue, leptospirosis, and snake bite cannot be found in text books from the west. Rapid increase in new information has reduced the shelf life of books with new editions published every four years. It is the duty of the teacher to evaluate new information and then decide how to fit this information to suit the student and the local context. Therefore we strongly rely on lectures to give information on knowledge of common and important diseases in Sri Lanka and their management.

Students learn some skills from what they see and by imitation of their teachers. Conscious effort must be made to improve on everything clinicians do during ward rounds as to what they do and how they do will have a clear impact on students. This process of role modeling is a powerful method of showing the students correct attitudes, values, ethics, communication skills, patterns of thinking and behavior while on the job in the clinical setting (3). Emphasis must always be made to treat patients as they are, rather than mere cases.

Teacher is no longer seen mainly as an information provider or a walking encyclopedia. With the shift towards student centered learning students must be helped to learn themselves (facilitator role) in small group settings such as in clinical ward classes where they can come out with ideas to solve problems faced by the patient. This will prepare them to become lifelong independent learners. During small group sessions (tutorials or small group ward/clinic discussions) facilitation must be done in a nonthreatening environment encouraging students to come out freely with their ideas without any fear or inhibition. Mentoring is a long-term relationship with a responsibility to provide the support, knowledge, and impetus that can facilitate professional success of a student. A teacher should be available to help students to overcome stress whenever it occurs during their stressful medical career as they want and expect their teachers to be a source of help (4). It is therefore important to play the role of a mentor whenever the need arises to discuss whatever difficulties the students may face in the learning environment. This will also help to identify weaker students early in their career (e.g. by student $\log$ book assessment) and necessary guidance given to them at relevant stages.

Assessing students (role of assessor) is an integral part of the teaching job in higher education (5). It must be ensured that the student assessments are valid, fair and in line with course objectives. Students should ideally be assessed throughout their course (log book and OSCE) and also at the end of the course at the final MBBS examination. In addition planning and implementation of the curriculum is an important role for teacher (role of planner). Most medical schools in Sri Lanka have made changes to their curricula to keep up with the recent trends in medical education. Traditional subject-based and discipline-based courses are now gradually moving into integrated and problem-based teaching methods (6). Such teaching programmes are more difficult to plan but worth the effort. Well defined course objectives are important for effective learning. Once the objectives are defined, then the instructional and assessment strategies can be made more rational. This task presents a great challenge and requires a great deal of time and expertise.

With the developments in the field of medical education, the need of resource materials has increased. With the teaching becoming more students centered, students become much dependent on these materials. Students should be provided with the appropriate sources of information required to solve problems at hand and shown how to access 
information, and more importantly to critically evaluate the content before applying it to solve a problem. Further the introduction of handheld computers (palmtops) in medicine with the availability of e-books is likely to reduce the memory loads of the students and young doctors by providing formulae, normal values and drug doses available at the press of a button. This way the brain power can be diverted from simple memorization to more analytical and productive purposes. Producing study guides is important as it provides the focus for student activities, gives necessary information on the topic and assists in active student learning (7). Computer-based learning materials are another popular and student friendly way of learning available for the modern medical students and clinical teachers must possess a knowledge of the required computer technology. With the availability of computer technology more computer assisted learning resources like teaching videos, self assessment MCQ's and other self learning materials can be developed.

In addition to the duties highlighted above, the medical teacher cannot ignore other traditional duties including providing clinical care to patients, administrative duties, and research. Research plays an important and a significant role in the career of academic clinicians and teachers. They must be conscious of the need to be involved in clinical research and must reflect this need to the junior colleagues and students, so that they too will inculcate this attribute.

These apparently separate roles described above are often interconnected and closely related. For instance during a small group bedside teaching the teacher must be aware that he/she is also performing role modeling. Multiple teaching roles are needed during a single clinical teaching and a good teacher will move instinctively between different roles (8). It is not practical for a good teacher to be equally competent in all the roles. Majority of teachers will have to perform a number of roles and the role of information provider is considered as an essential role. The roles may vary depending on the aims of a course, stage of a student in their carrier, and the type of the curriculum of a medical school.
Lectures should be periodically evaluated by student feedback as this will help to improve and maintain highest quality of teaching. Self evaluation is a powerful method of obtaining feedback. Clinical teachers can listen to audiotapes or watch videos of their encounters with students. Medical schools should be able to assist with this process. Sharing a video with a trusted colleague is often helpful, and sharing with a respected and more experienced educator may offer insights on how to improve further.

A key determinant of the success of clinical teaching is its organization. Teaching and learning activities need to be carefully scheduled to minimize competition between clinical and teaching duties. When clinical duties and teaching duties compete for time, clinical duties usually take priority. As such, the formal teaching sessions should be arranged keeping in mind always the clinical duties of the teachers in order to avoid them handing over teaching sessions to junior colleagues in the team.

\section{References}

1. Rowntree D. Teaching through Self-instruction: How to develop Open Learning Materials, Kogan Page, London, 1990.

2. Brew A, Boud, D. Preparing for new academic role: an holistic approach to development, International Journal of Academic Development 1996; 1(2): 17-25.

3. Campos-Outcalt D, Watkins AJ, Bastacky S. The effects of medical school curricula, faculty role models and biomedical research support on choice of generalist physician careers: a review of quality assessment of the literature, Academic Medicine 1995: 70(7): 11-619.

4. Grayson A, Clarke DD \& Miller H. Help-seeking among students: are lecturers seen as a potential source of help? Studies in Higher Education 1998; 23(2): 143-154.

5. Piper DW. Are Professors Professional? The Organisation of University Examination, Higher Education Policy, Series 25. London, Jessica Kingly Publishers, 1994.

6. Harden RM. The integration ladder: A tool for curriculum planning and evaluation. Medical education 2000; 34: 551557.

7. Harden RM, Laidlaw JM \& Hesketh EA. AMEE Medical Education Guide No. 16: Study Guides - their use and preparation. Medical Teacher 1999; 21(3): 248-265.

8. White R, Evan C. Clinical teaching in Nursing. London, Chapman \& Hall, 1991. 